\title{
Article \\ Risk Groups for SARS-CoV-2 Infection among Healthcare Workers: Community versus Hospital Transmission
}

\author{
Fatihan Pınarlık ${ }^{1,2,3}$ (D) Zeliha Genç ${ }^{4}\left(\mathbb{D}\right.$, Mahir Kapmaz $^{4}$, Süda Tekin ${ }^{1,4}$ and Önder Ergönül ${ }^{1,3, * \mathbb{C}}$ \\ 1 Department of Infectious Diseases and Clinical Microbiology, School of Medicine, Koc University, \\ 34010 Istanbul, Turkey; fpinarlik13@ku.edu.tr (F.P.); suda.tekin@gmail.com (S.T.) \\ 2 Graduate School of Health Sciences, Koc University, 34450 Istanbul, Turkey \\ 3 Koç University İşbank Center for Infectious Diseases (KUISCID), Koc University Hospital, \\ 34010 Istanbul, Turkey \\ 4 Infectious Diseases and Clinical Microbiology, Koc University Hospital, 34010 Istanbul, Turkey; \\ zakbulut@ku.edu.tr (Z.G.); mahirkapmaz@yahoo.com (M.K.) \\ * Correspondence: oergonul@ku.edu.tr
}

Citation: Pınarlık, F.; Genç, Z.; Kapmaz, M.; Tekin, S.; Ergönül, Ö. Risk Groups for SARS-CoV-2 Infection among Healthcare Workers: Community versus Hospital Transmission. Infect. Dis. Rep. 2021, 13, 724-729.

https://doi.org/10.3390/idr13030067

Academic Editor: Maria Chironna

Received: 17 June 2021

Accepted: 10 August 2021

Published: 13 August 2021

Publisher's Note: MDPI stays neutral with regard to jurisdictional claims in published maps and institutional affiliations.

Copyright: (c) 2021 by the authors. Licensee MDPI, Basel, Switzerland. This article is an open access article distributed under the terms and conditions of the Creative Commons Attribution (CC BY) license (https:/ / creativecommons.org/licenses/by/ $4.0 /)$.

\begin{abstract}
Background: We aimed to detect the risk factors for SARS-CoV-2 infection among healthcare workers (HCWs) in 2020 before the vaccination era. Methods: We surveyed SARS-CoV-2 infection among the HCWs in a hospital through screening for antibody levels and the detection of viral RNA by RT-PCR between May 2020 and December 2020. Occupational and non-occupational potential predictors of disease were surveyed for the HCWs included in this study. Results: Among 1925 personnel in the hospital, 1732 were included to the study with a response rate of $90 \%$. The overall infection rate of HCWs was $16.3 \%$ at the end of 2020 , before vaccinations started. In the multivariate analysis, being janitorial staff (OR: 2.24, CI: 1.21-4.14, $p=0.011$ ), being a medical secretary (OR: 4.17, CI: 2.12-8.18, $p<0.001$ ), having at least one household member with a COVID-19 diagnosis (OR: 8.98, CI: 6.64-12.15, $p<0.001$ ), and number of household members > 3 (OR: 1.67, CI: 1.26-2.22, $p<0.001)$ were found to be significantly associated with SARS-CoV-2 infection. Conclusions: Medical secretaries and janitorial staff were under increased risk of SARS-CoV-2 infection. The communityhospital gradient can explain the mode of transmission for infection among HCWs. In the setting of this study, community measures were less strict, whereas hospital infection control was adequate and provided necessary personal protective equipment. Increasing risk in larger households and households with diagnosed COVID-19 patient indicates the community-acquired transmission of the infection.
\end{abstract}

Keywords: healthcare workers; COVID-19; risk factors; seroprevalence; predictor

\section{Introduction}

The protection of HCWs from infection is strategic for the management of the pandemic. Therefore, since the beginning of the pandemic, HCWs have been screened for viral RNA and antibody levels to detect the level of infection and to determine the risk factors among HCWs. In seroprevalence studies, risk factors have been reported as being black [1-7], being male [5,8,9], working in frontline [9-13], working in an emergency department [6,7], working in an intensive care unit [14], or working in a laboratory [11]. The availability of PPE is important for protection from infection $[5,15]$. Some studies have reported that non-occupational risk factors such as household contact can increase seropositivity $[3,6,16,17]$. A recent meta-analysis revealed that male gender, ethnicity, and number of household contacts are associated with higher risks of infection [18].

Detailed and well-designed studies are needed to develop policies for the protection of HCWs. In this study, we aimed to determine the level of SARS-CoV-2 infection among $\mathrm{HCWs}$ and describe the predictive factors of the pre-vaccination era. 


\section{Materials and Methods}

\subsection{Study Design and Participants}

We used the STROBE guideline checklist (Supplementary Materials). We intended to include all HCWs in the hospital. HCWs were reached via e-mails and internal phone calls. Participation was voluntary, and participants were free to leave the study at any time without stating an excuse. All participants were called for antibody-level testing at the end of the first (from May 2020 to the end of August 2020) and second waves (from September 2020 to the end of December 2020) of the pandemic before vaccination and the emergence of variants.

Participants with past disease proven by seropositivity or current disease spotted by RT-PCR were put in the "infection" group, whereas seronegative and PCR-negative participants were placed in the "no infection" group. All participants were surveyed for demographic, occupational, and non-occupational risk factors that might be indicators for SARS-CoV-2 infection.

We screened HCWs for past SARS-CoV-2 infection via serum antibody levels using Elecsys Anti-SARS-CoV (Roche Diagnostics) kits. For the detection of current infection in symptomatic HCWs, nasopharyngeal swap samples were tested for viral RNA via RT-PCR. Data collection was terminated by the end of 2020 after the introduction of SARS-CoV-2 vaccines in Turkey.

\subsection{Statistical Analysis}

All data were collected and stored in a secure database to protect patient confidentiality. Data were analyzed by using the Stata 16 computer program. The chi-squared test was used for binary parameters, and the Mann-Whitney U test was used for continuous variables. Statistically significant risk factors were tested with multivariate analysis, and non-significant risk factors were eliminated in a stepwise fashion.

\subsection{Ethical Approval}

The study was approved by the Republic of Turkey Ministry of Health (No: 2021-0416T10_28_09) and the Koç University Institutional Review Board (No: 2021.254.IRB1.086).

\section{Results}

Out of 1925,1732 (90\%) HCWs responded and volunteered to participate in the study; $67.3 \%$ were female, and the median age was 28 (min: 18; max: 66). By the end of 2020, the rate of SARS-CoV-2 infection among HCWs was $16.3 \%$ before the vaccination era.

Comorbidities were reported in $4.4 \%$ of HCWs. The presence of any comorbidity was associated with infection ( $p=0.043$; Table 1$)$. The professional distribution was dominated by nurses $(48.5 \%)$ and physicians $(11.7 \%)$ in the hospital. In the univariate analysis, being a medical secretary or janitorial staff were found to be associated with infection (Table 1).

For occupational risk factors, working in the pandemic ward was not found to be associated with infection. However, the inappropriate use of PPE by HCWs despite patients wearing masks was associated with an increased risk of infection. On the other hand, the proper use of PPE in HCWs performing intubation was associated with a decreased risk of infection. Additionally, having more than three years of experience in the hospital was found to be associated with a decreased risk of infection, whereas contact with a COVID-19 patient was found to be associated with an increased risk.

Three non-occupational risk factors were investigated in this study. In the univariate analysis, using public transportation was not found to be associated with infection $(p=0.194)$. However, the presence of a diagnosed COVID-19 patient in household and household size were both found to be significantly $(p<0.001)$ associated with infection.

In the multivariate analysis, being janitorial staff (OR: 2.24, CI: 1.21-4.14, $p=0.011$ ), being a medical secretary (OR: 4.17, CI: 2.12-8.18, $p<0.001$ ), having at least one household member with a COVID-19 diagnosis (OR: 8.98, CI: 6.64-12.15, $p<0.001$ ), and number of 
household members $>3$ (OR: 1.67, CI: 1.26-2.22, $p<0.001$ ) were found to be significantly associated with SARS-CoV-2 infection (Table 2).

Table 1. Characteristics and risk factors for SARS-CoV-2 infection.

\begin{tabular}{|c|c|c|c|c|}
\hline & $\begin{array}{c}\text { Total } \\
n=1732(\%)\end{array}$ & $\begin{array}{c}\text { Infection } \\
n=283(\%)\end{array}$ & $\begin{array}{c}\text { No Infection } \\
n=1449(\%)\end{array}$ & $p$-Value \\
\hline \multicolumn{5}{|l|}{ Demographics } \\
\hline Female Gender & $1166(67.3)$ & $189(66.8)$ & $977(67.4)$ & 0.833 \\
\hline Median Age (IQR) & & $27(24-34)$ & $28(24-35)$ & 0.198 \\
\hline \multicolumn{5}{|l|}{ Comorbidities } \\
\hline Any Comorbidity & $77(4.4)$ & $19(6.7)$ & $58(4.0)$ & 0.043 \\
\hline Hypertension & $20(1.2)$ & $3(1.0)$ & $17(1.2)$ & 0.871 \\
\hline Type 2 Diabetes & $16(0.9)$ & $2(0.7)$ & $14(1.0)$ & 0.676 \\
\hline Renal Disease & $17(1.0)$ & $5(1.8)$ & $12(0.8)$ & 0.143 \\
\hline Rheumatologica Disease & $8(0.5)$ & $2(0.7)$ & $6(0.4)$ & 0.507 \\
\hline Asthma & $5(0.3)$ & $1(0.4)$ & $4(0.3)$ & 0.825 \\
\hline \multicolumn{5}{|l|}{ Profession } \\
\hline Nurse & $840(48.5)$ & $123(43.5)$ & $717(49.5)$ & 0.064 \\
\hline Physician & $203(11.7)$ & $24(8.5)$ & $179(12.4)$ & 0.064 \\
\hline Porter & $129(7.4)$ & $23(8.1)$ & $106(7.3)$ & 0.634 \\
\hline Janitorial Staff & $66(3.8)$ & $17(6.0)$ & $49(3.4)$ & 0.035 \\
\hline Anesthesia Technician & $52(3.0)$ & $6(2.1)$ & $46(3.2)$ & 0.342 \\
\hline Laboratory Technician & $52(3.0)$ & $11(3.9)$ & $41(2.8)$ & 0.340 \\
\hline Medical Secretary & $46(2.6)$ & $20(7.0)$ & $26(1.8)$ & $<0.001$ \\
\hline Security Staff & $41(2.4)$ & $4(1.4)$ & $37(2.6)$ & 0.249 \\
\hline Radiology Technician & $39(2.2)$ & $6(2.1)$ & $33(2.3)$ & 0.870 \\
\hline Pharmacy & $38(2.2)$ & $9(3.2)$ & $29(2.0)$ & 0.216 \\
\hline Physiotherapist & $8(0.5)$ & $2(0.7)$ & $6(0.4)$ & 0.507 \\
\hline Other & $218(12.6)$ & $38(13.4)$ & $180(12.4)$ & 0.641 \\
\hline \multicolumn{5}{|l|}{ Occupational Risk Factors } \\
\hline Working in COVID-19 Unit & $302(17.4)$ & $38(13.4)$ & $264(18.2)$ & 0.052 \\
\hline$>3$ Years of Experience & $882(50.9)$ & $123(43.5)$ & $759(52.4)$ & 0.006 \\
\hline Contact with Probable/Diagnosed COVID-19 Patient & $1038(59.9)$ & $188(66.4)$ & $850(58.7)$ & 0.015 \\
\hline Inappropriate PPE during Invasive Procedure to the Patient & $182(10.5)$ & $32(11.3)$ & $150(10.4)$ & 0.632 \\
\hline Inappropriate PPE although the Patient Has a Mask & $160(9.2)$ & $32(11.3)$ & $128(8.8)$ & 0.009 \\
\hline Contact with ICU Maskless Patient with PPE & $408(23.6)$ & $60(21.2)$ & $348(24.0)$ & 0.307 \\
\hline Contact with Intubated ICU Patient with PPE & $293(16.9)$ & $35(12.4)$ & $258(17.8)$ & 0.026 \\
\hline \multicolumn{5}{|l|}{ Non-Occupational Risk Factors } \\
\hline Diagnosed COVID-19 Patient in Household & $260(15.0)$ & $131(46.3)$ & $129(8.9)$ & $<0.001$ \\
\hline Household Size $>3$ People & $792(45.7)$ & $158(55.8)$ & $634(43.8)$ & $<0.001$ \\
\hline Public Transportation Use & $1383(79.8)$ & $234(82.7)$ & $1149(79.3)$ & 0.194 \\
\hline
\end{tabular}

Table 2. The predictors of SARS-CoV-2 infection among HCWs.

\begin{tabular}{lcccccc}
\hline & \multicolumn{3}{c}{ Univariate Analysis } & \multicolumn{3}{c}{ Multivariate Analysis } \\
\hline \multicolumn{1}{c}{ Risk Factors } & OR & CI & $p$ & OR & CI & $p$ \\
Janitorial Staff & 1.82 & $1.04-3.22$ & 0.037 & 2.24 & $1.21-4.14$ & 0.011 \\
Medical Secretary & 4.16 & $2.29-7.56$ & $<0.001$ & 4.17 & $2.12-8.18$ & $<0.001$ \\
Diagnosed Patient in Household & 8.82 & $6.56-11.85$ & $<0.001$ & 8.98 & $6.64-12.15$ & $<0.001$ \\
Number of Household Members $>3$ & 1.62 & $1.26-2.10$ & $<0.001$ & 1.67 & $1.26-2.22$ & $<0.001$ \\
\hline
\end{tabular}

\section{Discussion}

In this screening study before the era of vaccinations and variants, we investigated the risk factors associated with COVID-19 infection among HCWs. We detected that being a medical secretary (OR: 4.17, CI: 2.12-8.18, $p<0.001$ ) or janitorial staff (OR: 2.24, CI: $1.21-4.14, p=0.011$ ) was associated with increased risk of infection (Table 2). Though administrative staff have been found to have decreased risk in some studies $[3,6,19]$, others have suggested that the risk of infection is higher for registrars [20], administrative employees [21], account staff [22], and janitorial staff $[6,19,21,22]$. The detection of being a 
medical secretary or janitorial staff as independent risk factors could be explained by the uncontrolled social gatherings because frontline workers are protected by strict measures. Contejean et al. suggested that close contact with coworkers without a mask can be a risk factor for seropositivity [23]. Doctors and nurses are provided with larger office spaces that prevented crowded gatherings, although medical secretaries and janitorial staff had small offices and changing rooms. Additionally, informative seminars and posters about SARS-CoV-2 infection were provided to the clinical HCWs, but critical health literacy [24] might not be achieved among medical secretaries and janitorial staff. Increased risk was not caused by the lack of PPE because all HCWs in the hospital were provided with necessary masks, shields, gowns, and other protective equipment where necessary.

In our study, among the occupational risk factors, contact with COVID-19 patients, and inappropriate use of PPE were found to be associated with an increased risk of infection. On the other hand, working experience and contact with intubated ICU patients with PPE was found to decrease the risk. These findings suggest that the transmission of SARS-CoV-2 can be blocked with the appropriate use of PPE. In settings where PPE are readily available and HCWs are trained against SARS-CoV-2 transmission, occupational transmission could be minimized. We suggest the term "community-hospital gradient" to explain the shift from the occupational-acquired form of SARS-CoV-2 to the community-acquired form. The community-hospital gradient suggests a more dynamic model, and it can be useful to explain the uncertainty that some studies $[3,6,16,17]$ have revealed risk factors suggesting transmission from the community but whereas others [9-14] have highlighted occupational transmission. The community-hospital gradient favors hospital transmission in the setting of the strict community control of SARS-CoV-2 by mask mandates and full lockdowns, along with a lack of protective measures in the hospital caused by increased workloads and sub-optimal PPE provision. Nevertheless, the community-hospital gradient can favor community transmission for hospitals where PPE and infection control are provided, but community-level measures are less strict and the social setting promotes close contact. In such a community, household size and diagnosed patient in the household were found to be associated with an increased risk of infection. The household size factor had not been reported in previous research, although household contact was found to be associated with increased risk in several studies $[3,6,16,17]$.

Gender and age were studied as demographic risk factors for disease. However, no statistically significant association was found. Some studies in the literature have suggested that the male gender is a risk factor for SARS-CoV-2 infection [5,8,9], though other studies [1-4,6,10-12,16,17,25-30] have failed to show any significant association, which matches our findings. It should be noted that HCWs belong to a working population in which the median and maximum ages are lower than those of the general population. Therefore, the low power of our study, with a small sample of older HCWs, might not have been sufficient to reach statistical significance.

Similarly, participants with comorbidities constituted only $4.4 \%$ of the studied population, thus showing that the studied HCW population is healthier than the general population. Though having at least one comorbidity was found to associated with an increased risk of SARS-CoV-2 infection in the univariate analysis, the low number of participants with chronic disease (77 participants) decreased our capacity to demonstrate any association with each comorbidity, separately. Some studies with large sample sizes were not able to show the risk associated with infection [5,9]. On the other hand, Delmas et al. suggested that diabetes is associated with higher seroprevalence (OR: 1.78, CI: 1.04-3.03) [29], whereas Goenka et al. argued that cardiovascular diseases are associated with lower seroprevalence (OR: 0.38, CI: 0.15-0.96) [26].

A strength of our study was the inclusion of $90 \%$ of the HCWs in the hospital to avoid selection bias. However, there were two main limitations of this study. The first one was the recall bias of participants. We limited recall bias by completing the surveys before serological and PCR testing, as well as by using the recording system of the occupational 
health unit. Another limitation was that this study only covered one hospital in Turkey, and results may have been affected by hospital- and country-specific characteristics.

\section{Conclusions}

By the end of 2020, just before the era of vaccination and variants, the rate of SARSCoV-2 infection was $16.3 \%$ among HCWs in our hospital. Medical secretaries and janitorial staff were under an increased risk of SARS-CoV-2 infection because of their exposure in the community or because they were neglected since they were not in the frontline. Increasing risk in larger households and households with a diagnosed COVID-19 patient was found to indicate the community-acquired transmission of infection. The community-hospital gradient favors community transmission in the case of adequate protective measures being implemented in the hospital but insufficient measures being implemented in the community. Healthcare workers who are not in the frontline should also be included in education programs.

Supplementary Materials: The following are available online at https:/ /www.mdpi.com/article/10 $.3390 /$ idr13030067/s1; STROBE Statement—Checklist of items that should be included in reports of cross-sectional studies.

Author Contributions: Conceptualization, F.P. and Ö.E.; methodology, Ö.E.; formal analysis, F.P. and Ö.E.; data collection, Z.G. and M.K. and S.T.; data curation, F.P. and Ö.E.; writing-original draft preparation, F.P. and Ö.E.; writing—review and editing, F.P. and Ö.E.; visualization, F.P. and Ö.E.; supervision, Ö.E.; project administration, Ö.E. All authors have read and agreed to the published version of the manuscript.

Funding: This research received no external funding.

Institutional Review Board Statement: The study was conducted according to the guidelines of the Declaration of Helsinki, and approved by the Institutional Review Board (or Ethics Committee) of Koc University (No:2021.254.IRB1.086).

Informed Consent Statement: Informed consent was obtained from all subjects involved in the study.

Data Availability Statement: Not applicable.

Acknowledgments: Roche Diagnostics provided Elecsys Anti-SARS-CoV kits.

Conflicts of Interest: The authors declare no conflict of interest.

\section{References}

1. Brant-Zawadzki, M.; Fridman, D.; Robinson, P.A.; Zahn, M.; Chau, C.; German, R.; Breit, M.; Bock, J.R.; Hara, J. SARS-CoV-2 antibody prevalence in health care workers: Preliminary report of a single center study. PLoS ONE 2020, 15, e0240006. [CrossRef] [PubMed]

2. Racine-Brzostek, S.E.; Yang, H.S.; Chadburn, A.; Orlander, D.; An, A.; Campion, T.R.; Yee, J.; Chen, Z.; Loda, M.; Zhao, Z.; et al. COVID-19 Viral and Serology Testing in New York City Health Care Workers. Am. J. Clin. Pathol. 2020, 154, 592-595. [CrossRef] [PubMed]

3. Martin, C.A.; Patel, P.; Goss, C.; Jenkins, D.R.; Price, A.; Barton, L.; Gupta, P.; Zaccardi, F.; Jerina, H.; Duraisingham, S.; et al. Demographic and occupational determinants of anti-SARS-CoV-2 IgG seropositivity in hospital staff. J. Public Health 2020, 1-12. [CrossRef]

4. Jones, C.R.; Hamilton, F.W.; Thompson, A.; Morris, T.T.; Moran, E. SARS-CoV-2 IgG seroprevalence in healthcare workers and other staff at North Bristol NHS Trust: A sociodemographic analysis. J. Infect. 2021, 82, e24-e27. [CrossRef]

5. Self, W.H.; Tenforde, M.W.; Stubblefield, W.B.; Feldstein, L.R.; Steingrub, J.S.; Shapiro, N.I.; Ginde, A.A.; Prekker, M.E.; Brown, S.M.; Peltan, I.D.; et al. Seroprevalence of SARS-CoV-2 Among Frontline Health Care Personnel in a Multistate Hospital Network-13 Academic Medical Centers, April-June 2020. MMWR Morb. Mortal. Wkly. Rep. 2020, 69, 1221-1226. [CrossRef]

6. Eyre, D.W.; Lumley, S.F.; O’Donnell, D.; Campbell, M.; Sims, E.; Lawson, E.; Warren, F.; James, T.; Cox, S.; Howarth, A.; et al. Differential occupational risks to healthcare workers from SARS-CoV-2 observed during a prospective observational study. eLife 2020, 9, e60675. [CrossRef]

7. Sydney, E.R.; Kishore, P.; Laniado, I.; Rucker, L.M.; Bajaj, K.; Zinaman, M.J. Antibody evidence of SARS-CoV-2 infection in healthcare workers in the Bronx. Infect. Control. Hosp. Epidemiol. 2020, 41, 1348-1349. [CrossRef]

8. Moscola, J.; Sembajwe, G.; Jarrett, M.; Farber, B.; Chang, T.; McGinn, T.; Davidson, K.W.; Northwell Health, C.-R.C. Prevalence of SARS-CoV-2 Antibodies in Health Care Personnel in the New York City Area. JAMA 2020, 324, 893-895. [CrossRef] [PubMed] 
9. Iversen, K.; Bundgaard, H.; Hasselbalch, R.B.; Kristensen, J.H.; Nielsen, P.B.; Pries-Heje, M.; Knudsen, A.D.; Christensen, C.E.; Fogh, K.; Norsk, J.B.; et al. Risk of COVID-19 in health-care workers in Denmark: An observational cohort study. Lancet Infect. Dis. 2020, 20, 1401-1408. [CrossRef]

10. Ann-Sofie, R.; Sebastian, H.; Anna, M.n.; August Jernbom, F.; Katherina, A.; Henry, N.; Lena, G.; Ann-Christin, S.; Leo, H.; Ben, M.; et al. SARS-CoV-2 exposure, symptoms and seroprevalence in healthcare workers in Sweden. Nat. Commun. 2020, 11, 1-8.

11. Andrea, C.; Valeria, G.; Teresa, E.; Mattia, T.; Silvia, F.; Lucio, B.; Elisa, B.; Sabrina, A.; Filippo, L.; Marco, N.; et al. Risk for SARS-CoV-2 Infection in Healthcare Workers, Turin, Italy. Emerg. Infect. Dis. 2021, 27, 303-305.

12. Lidström, A.K.; Sund, F.; Albinsson, B.; Lindbäck, J.; Westman, G. Work at inpatient care units is associated with an increased risk of SARS-CoV-2 infection; a cross-sectional study of 8679 healthcare workers in Sweden. Upsala J. Med. Sci. 2020, 125, 305-310. [CrossRef]

13. Grant, J.J.; Wilmore, S.M.S.; McCann, N.S.; Donnelly, O.; Lai, R.W.L.; Kinsella, M.J.; Rochford, H.L.; Patel, T.; Kelsey, M.C.; Andrews, J.A. Seroprevalence of SARS-CoV-2 antibodies in healthcare workers at a London NHS Trust. Infect. Control. Hosp. Epidemiol. 2021, 42, 212-214. [CrossRef]

14. Blairon, L.; Mokrane, S.; Wilmet, A.; Dessilly, G.; Kabamba-Mukadi, B.; Beukinga, I.; Tré-Hardy, M. Large-scale, molecular and serological SARS-CoV-2 screening of healthcare workers in a 4-site public hospital in Belgium after COVID-19 outbreak. J. Infect. 2021, 82, 159-198. [CrossRef]

15. Madran, B.; Keske, Ş.; Beşli, Y.; Bozkurt, İ.; Ergönül, Ö. The Risk of SARS-CoV-2 Infection Among Healthcare Workers. Infect. Dis. Clin. Microbiol. 2020, 2, 54-60. [CrossRef]

16. Steensels, D.; Oris, E.; Coninx, L.; Nuyens, D.; Delforge, M.L.; Vermeersch, P.; Heylen, L. Hospital-Wide SARS-CoV-2 Antibody Screening in 3056 Staff in a Tertiary Center in Belgium. JAMA 2020, 324, 195-197. [CrossRef] [PubMed]

17. Dimcheff, D.E.; Schildhouse, R.J.; Hausman, M.S.; Vincent, B.M.; Markovitz, E.; Chensue, S.W.; Deng, J.; McLeod, M.; Hagan, D.; Russell, J.; et al. Seroprevalence of severe acute respiratory syndrome coronavirus-2 (SARS-CoV-2) infection among Veterans Affairs healthcare system employees suggests higher risk of infection when exposed to SARS-CoV-2 outside the work environment. Infect. Control. Hosp. Epidemiol. 2021, 42, 392-398. [CrossRef]

18. Kayı, İ.; Madran, B.; Keske, Ş.; Karanfil, Ö.; Arribas, J.R.; Pshenichnaya, N.; Petrosillo, N.; Gönen, M.; Ergönül, Ö. The Seroprevalence of SARS-CoV-2 Antibodies among Healthcare Workers before the Era of Vaccination: A Systematic Review and Meta-Analysis. Available online: https:/ / pubmed.ncbi.nlm.nih.gov/34116205/ (accessed on 13 August 2021).

19. Makadia, J.S.; Gohel, M.G.; Chakrabarti, C.; Pethani, J.D. Prevalence of Seropositivity to SARS-CoV-2 among Health Care Workers in Tertiary COVID-19 Hospital, Ahmedabad, Gujarat. J. Clin. Diagn. Res. 2021, 15, 1-4.

20. Rodriguez, A.; Arrizabalaga-Asenjo, M.; Fernandez-Baca, V.; Lainez, M.P.; Al Nakeeb, Z.; Garcia, J.D.; Payeras, A. Seroprevalence of SARS-CoV-2 antibody among healthcare workers in a university hospital in Mallorca, Spain, during the first wave of the COVID-19 pandemic. Int. J. Infect. Dis. 2021, 105, 482-486. [CrossRef]

21. Musa, S.; Abdel Alem, S.; Amer, K.; Elnagdy, T.; Hassan, W.A.; Ali, M.A.; Gaber, Y.; Badary, H.A.; Tantawi, O.; Abdelmoniem, R.; et al. Prevalence of SARS-CoV-2 Infection and Dynamics of Antibodies Response among Previously Undiagnosed Healthcare Workers in a University Hospital: A Prospective Cohort Study. Available online: https://pubmed.ncbi.nlm.nih.gov/34175238/ (accessed on 13 August 2021).

22. Mahto, M.; Banerjee, A.; Biswas, B.; Kumar, S.; Agarwal, N.; Singh, P.K. Seroprevalence of IgG against SARS-CoV-2 and its determinants among healthcare workers of a COVID-19 dedicated hospital of India. Am. J. Blood Res. 2021, 11, 44-52. [PubMed]

23. Contejean, A.; Leporrier, J.; Canoui, E.; Fourgeaud, J.; Mariaggi, A.A.; Alby-Laurent, F.; Lafont, E.; Beaudeau, L.; Rouzaud, C.; Lecieux, F.; et al. Transmission Routes of Severe Acute Respiratory Syndrome Coronavirus 2 Among Healthcare Workers of a French University Hospital in Paris, France. Open Forum Infect. Dis. 2021, 8, ofab054. [CrossRef] [PubMed]

24. Chinn, D. Critical health literacy: A review and critical analysis. Soc. Sci. Med. 2011, 73, 60-67. [CrossRef] [PubMed]

25. Mina, P.; Andreas, K.; Ioanna, D.P.; Dimitrios, B.; Konstantinos, P.; Sotirios, R.; Maria, P.; Edison, J.; Konstantinos, P.; Konstantinos, L.; et al. Antibodies against SARS-CoV-2 among health care workers in a country with low burden of COVID-19. PLoS ONE 2020, $15, \mathrm{e} 0243025$.

26. Goenka, M.; Afzalpurkar, S.; Goenka, U.; Das, S.S.; Mukherjee, M.; Jajodia, S.; Shah, B.B.; Patil, V.U.; Rodge, G.; Khan, U.; et al. Seroprevalence of COVID-19 Amongst Health Care Workers in a Tertiary Care Hospital of a Metropolitan City from India. J. Assoc. Physicians India 2020, 68, 14-19. [CrossRef] [PubMed]

27. Jeremias, A.; Nguyen, J.; Levine, J.; Pollack, S.; Engellenner, W.; Thakore, A.; Lucore, C. Prevalence of SARS-CoV-2 Infection Among Health Care Workers in a Tertiary Community Hospital. JAMA Intern. Med. 2020, 180, 1707-1709. [CrossRef] [PubMed]

28. Plebani, M.; Padoan, A.; Fedeli, U.; Schievano, E.; Vecchiato, E.; Lippi, G.; Lo Cascio, G.; Porru, S.; Palù, G. SARS-CoV-2 serosurvey in health care workers of the Veneto Region. Clin. Chem. Lab. Med. 2020, 58, 2107-2111. [CrossRef] [PubMed]

29. Delmas, C.; Plu-Bureau, G.; Canoui, E.; Mouthon, L.; Meritet, J.F. Clinical Characteristics and Persistence of SARSCoV-2 IgG Antibodies in 4607 French Healthcare Workers: Comparison with European Countries. Available online: https://www.cambridge.org/core/journals/infection-control-and-hospital-epidemiology/article/clinical-characteristicsand-persistence-of-sarscov2-igg-antibodies-in-4607-french-healthcare-workers-comparison-with-european-countries / DA5F5 7BEF93E49D6058C3BA0AACA1237 (accessed on 13 August 2021).

30. Xu, X.; Sun, J.; Nie, S.; Li, H.; Kong, Y.; Liang, M.; Hou, J.; Huang, X.; Li, D.; Ma, T.; et al. Seroprevalence of immunoglobulin M and $\mathrm{G}$ antibodies against SARS-CoV-2 in China. Nat. Med. 2020, 26, 1193-1195. [CrossRef] 